\title{
Posterior Spinal Artery
}

National Cancer Institute

\section{Source}

National Cancer Institute. Posterior Spinal Artery. NCI Thesaurus. Code C12876.

An artery arising from the vertebral artery at the level of the medulla oblong ata that descends along the posterior roots of the spinal nerves on each side of the spinal cord with branches supplying the spinal cord, pia mater and medulla. 